\title{
El origen del marketing político en Jalisco
}

\section{LUIS FERNANDO SANCHEZ*}

Resumen. El estudio explica y reüne diversas vartables de andisis para la comprension teorica del marketing polftico, $y$ en particular, describe $y$ examina los elementos del sistema politico y el sistema de medios causantes del surgimiento $y$ desarrollo del marketing político en el entorno jalisciense. De esta manera, se efectua un andisis de la ley electoral y de aquellas reglamentaciones vinculadas al uso de los medios de comunicación durante los procesos electorales y su relación con el uso del marketing político; establece que el surgimiento del marketing politico en Jalisco se encuentra ligado a la presencia de procesos electorales más competidos $y$ democráticos, asi como al tipo de reglamentaciones electorales en materia de comunicactón política; examina el comportamiento de los medios de información durante los procesos electorales, $y$ su contribución a la realización de procesos electorales más igualitarios y equitativos, pero tambiên al auge de la videopolitica; sostiene que la utilización de los medios de información como instrumento propagandístico de los partidos y candidatos, sobreviene por el carácter laxo de las reglamentaciones en materia de comunicación politica; establece que los actores politicos se ban ocupado mas por atender las cuestiones relativas al acceso, la distribución equitativa de tiempos y expacios en los medios, que por el contenido de las campañas electorales; y finalmente afirma que la ley electoral en Jalisco (y las reglamentaciones que se desprenden de ella) son obsoletas en lo concerniente a normar las campañas electorales en los medios, el nuevo espacio piblico.

- Especialista en comunicación política. Centro Universitario de la Ciénega, Universidad de Guadalajara. Correo electrónico: fhernandosanchezoyahoo.com.mx 


\section{Introducción}

\section{T as campañas electorales en México y Jalisco se desarrollan cada vez más en los medios y para los medios. Los partidos y candidatos} gastan mayores recursos económicos en publicidad política mediática para hacer llegar sus mensajes al mayor número de electores, y así pretender posicionarse en sus mentes e influir en la orientación de sus votos. Es así que el uso del marketing político adquiere importancia pues se convierte (prácticamente) en la principal herramienta para conducir una campaña electoral, es cuando su utilización busca -en la praxispromover y legitimar candidatos o agrupaciones políticas para acceder o mantener el poder, y satisfacer (o pretender satisfacer) las necesidades y deseos de los ciudadanos o de una parte de éstos (Sánchez, 2003). Y es que los consultores políticos más que buscar un rasgo ideologico distintivo del actor político, trabajan en una característica personal para promoverla (Morato, 1989: 96; Ferrer, 1995: 148-150; Maarek, 1997: 58-59; Plasser, Scheucher y Senft, 1999: 97-98; Aceves, 2000: 40-42; Priess, 2000; Delarbre, 2001: 102-108).' Por tanto, lo que importa en la mayoría de los casos es la persona y no tanto sus propuestas políticas.

Al margen de la discusión vinculada al modo en el que el marketing político funciona, esto es, en cuanto a si promueve ideas o la imagen del candidato, tal vez convendría preguntarse también ¿qué factores influyen en el surgimiento y desartollo del marketing político? Específicamente en los casos de México y Jalisco parece ser una cuestión que ha sido poco examinada por los especialistas e investigadores.

Así pues, el presente escrito propone una explicación en torno al surgimiento y desarrollo del marketing político en Jalisco; efectúa un análisis de la ley electoral y aquellas reglamentaciones vinculadas al uso de los medios de comunicación durante los procesos electorales y su relación con el uso del marketing político; examina el comportamiento de los medios de información durante los procesos electorales, y su contribución a la realización de procesos electorales más igualitarios y equitativos, pero también al auge de la videopolítica; establece que el surgimiento del marketing político en Jalisco se encuentra ligado a la presencia de procesos electorales más competidos y democráticos; sostiene que la utilización de los medios de información como instrumento propagandístico de los partidos y candidatos, sobreviene por el carácter laxo de las reglamentaciones en materia de comunicación política, cuestión que se puede observar por los gastos realizados por los partidos durante los procesos electo-

- De acuerdo a una encuesta realizada por Plasser, Scheucher y Senft (1999) a los consultores y expertos europeos en manketing político, el $75 \%$ considera que un punto crucial de una campaña electoral es el candidato, es decir, establecer, transmitir y definir el perfil o la imagen del producto, el cual está constituido por la personalidad del candidato. 
rales. Después, el estudio expone los problemas que implican las actuales reglamentaciones en materia de comunicación política durante los procesos electorales. Del mismo modo, el análisis aquí realizado indica que los actores políticos se han ocupado más por atender los asuntos relativos al acceso, la distribución equitativa de tiempos y espacios en los medios, que por el contenido de las campañas electorales; y finalmente, establece que la ley electoral en Jalisco (y las reglamentaciones que se desprenden de ella) son obsoletas en lo concerniente a normar las campañas electorales en los medios, el nuevo espacio público.

\section{Factores que inciden en el surgimiento y aplicaciốn del marketing político}

Hoy en día, la utilización del marketing político posee diversas características e intensidades dependiendo del contexto en el que se encuentre, y es que de acuerdo con ciertos autores (Maarek, 1997; Plasser, Scheucher y Senft, 1999; Hennerberg, 2002; Salgado, 2002), su nacimiento y uso está condicionado por las particularidades de los subsistemas constitutivos del sistema político, el sistema de medios y el desarrollo de éstos, entie las que convienen subrayar: $a$ ) el sistema electoral, en el que se mencionan como factores determinantes: el principio de representación, ya sea mayoritario o proporcional; la duración de los periodos de gobierno, las reglas relativas a las candidaturas (por ejemplo, listas cerradas y bloqueadas, listas abiertas, listas cerradas y no bloqueadas), las leyes y reglamentaciones en materia de campañas electorales y de comunicación política, el tipo de financiamiento permitido (público o privado), los topes de gastos de campaña, el acceso a publicidad política en medios; la duración de las campañas electorales $\mathrm{y}$, la elaboración de las elecciones primarias y precampañas; b) el sistema de partidos, en el que se consideran: el número de partidos, su tamaño y la distancia ideológica entre ellos, el perfil desideologizado de éstos, y el debilitamiento de la lealtad partidista. Aunque también señalan la capacidad de la organización partidista para movilizar a los seguidores del partido; $c$ ) el sistema de gobierno, en éste los autores tomados en consideración por la presente investigación no señalan alguna relación entre el sistema de gobierno y el marketing político; sin embargo, tal vez exista una argumentación que se pueda inferir, ésta es, la desarrollada por Sartori, quien establece una concordancia entre el sistema presidencial y el incremento de la videopolítica; d) el sistema cultural; $e$ ) el sistema de medios, en el que influye: si son propiedad del Estado (públicos) o privados, o un sistema dual, el grado de diferenciación en el sistema de medios, el nivel de modernización, la autonomía de los medios, el rol profesional de los periodistas; y $f$ la tradición de las elecciones democráticas. 
El uso del marketing político no se puede explicar sin la existencia de la democracia, ya que ésta constituye uno de sus prerrequisitos. En Jalisco, el surgimiento de esta técnica sucede -como más adelante se examina- por el advenimiento de procesos electorales cada vez más competidos. Sin embargo, es la conjugación de otros factores del sistema politico y el sistema de medios lo que permite el desarrollo del marketing en la arena politica: serán el tipo de reglamentaciones electorales, el sistema de partidos, el sistema de gobierno, y los medios de comunicación los que darán un contexto favorable para su desarrollo, y aunque las primeras manifestaciones del marketing político se podrian encontrar en las elecciones de 1994 y 1995, es hasta las elecciones locales de 1997 cuando esas prácticas serán más claras.

\section{El sistema politico autoritario y el advenimiento} de la democracia politica en Jalisco

En lo sustancial, las prácticas ejercidas por el PRI nacional y el gobierno federal no difieren en mucho de las realizadas por la elite gobernante y los grupos de poder local al interior del PRI en el estado de Jalisco (en particular, de aquellas vinculadas con los procesos electorales). La estructura del Estado mexicano y en particular la del PRI permitía que esta organización nuviera gran influencia sobre las demás entidades de la República (Lujambio, 1995), de manera que el sistema de partido hegemónico se extendía a los otros ámbitos de gobierno. En este sentido, Jalisco no era la excepción, por lo que el PRI y la elite gobernante local (sin excluir, por supuesto, la posible y probable intervención de los dirigentes del orden nacional), se encargaban de que la competencia por el poder fuera más bien limitada, puesto que los partidos opositores podian participar en la contienda electoral, en realidad no les era permitido arrebatarle el poder a la coalición revolucionaria en el gobierno, pues hasta 1992 la oposición había conseguido, no sin problemas, el reconocimiento de apenas 76 puestos locales de representación política y de gobierno - hasta 1988 suman 36, y hasta 1992 otros 38- (Alonso: 1993). ${ }^{2}$ Cabe señalar que de acuerdo con Hurtado (1998), el PRI conservó el control del Congreso con más de $70 \%$ de los escaños entre los años de 1980 y 1995 , específicamente con un $76 \%$ entre los años de 1980 y 1989 y con un $70.6 \%$ entre 1989 y 1995 , incluso la figura de diputados de partido, que había sido creada en el ámbito federal en 1963 para incorporar a las fuerzas políticas minoritarias a los organos de representación política, es incorporada en Jalisco hasta 1980. Así, mientras en 1979 se

2 Once municipios, diez diputaciones federales de mayoría y tres locales todas éstas del PAN, cuatro gobiernos municipales del PARM, cinco del PDM de la izquierda, tres. 
introduce el sistema de representación proporcional en la cámara de diputados del Congreso de la Unión, en Jalisco se adopta hasta 1987. En este sentido, es preciso señalar que, si bien la figura de diputados de partido había permitido a las fuerzas políticas opositoras ingresar a los congresos estaduales, no obstante impedía que el PRI perdiera la mayoría calificada (66\%); esto es, el porcentaje necesario para aprobar, sin el consentimiento de la oposición, reformas a la Constitución local, ya sea, ofreciendo sólo un escaño al partido que rebasara el umbral de representación o colocando umbrales relativamente altos cuando se ofrecían más escaños (Lujambio, 2000). Se puede apreciar cómo sobresale la lentitud con la que los gobiernos prístas en Jalisco fueron adoptando las reformas electorales realizadas a nivel federal (cabe decir que 17 sistemas electorales estaduales ya habían legislado sobre la figura de los diputados de partido antes de la reforma de 1977).

Sin embargo, estas acciones de liberalización no serían suficientes para el ambiente político jalisciense -en particular con el gobierno de Cosio Vidaurri y los cuestionamientos que se produjeran a causa de su gestión- el cual experimentaría durante ese periodo cambios mayores, sobre todo por las presiones políticas de 1991 y 1992 en relación a que Jalisco se ajustara a los cambios llevados a cabo en el Congreso ${ }^{*}$ de la Unión en materia electoral, por las demandas relativas a que se respetaran los triunfos electorales de las diversas fuerzas políticas distintas al PRI, y en general, porque se respetara el voto y hubiera procesos electorales más transparentes (cuestión que se venía solicitando muchos años atrás); por los actos de corrupción y nepotismo cometidos por el gobierno de Cosío y el descontento por la concentración de los beneficios económicos durante su administración; a causa del sentimiento de inseguridad por parte de la población ante los ajustes de cuentas entre narcotraficantes y lavadólares y "ante una criminalidad incontenible"; por los problemas vinculados con las nominaciones a las candidaturas locales entre los grupos opositores priístas y la administración de Cosío en las elecciones de 1992; por las explosiones del 22 de abril de 1992 y el desalojo violento de los damnificados perpetrado el $1^{\circ}$ de junio de ese mismo año y el encubrimiento de los verdaderos responsables por esos actos; a causa del asesinato del cardenal Juan Jesús Posadas Ocampo; por el descontento respecto a la incapacidad gubernamental para afrontar los problemas de contaminación presentes todavía hasta 1994 por hidrocarburos en la zona metropolitana de Guadalajara; y por el problema de las carteras vencidas de los productores rurales. En fin, por el malestar de la población con respecto al gobierno Cosiísta (y el de Rivera Aceves) y por el incremento del apoyo electoral panista en los últimos procesos electorales; por el levantamiento armado en Chiapas y el asesinato del candidato del PRI a la presidencia de la República, Luis Donaldo Colosio; todo esto sería el escenario y posible motivo que produjera que el PAN ganara en los 
sucesivos procesos electorales (Alonso, 1986; 1995; Valdez, 1996), y que ganara en 199411 distritos de la zona metropolitana de Guadalajara; esto es, en donde se encontraba el $54.3 \%$ de la población jalisciense al mismo tiempo que ampliaba su votación en otros distritos rurales. $Y$ es que para Jorge Alonso serían varios factores los que influirían en el "auge" del voto panista como la tradición bipartidista tapatía, el repudio de nuevos votantes hacia el mal gobierno en la entidad, y la gran influencia de Diego Fernández de Cevallos fortalecida por el debate de mayo que lo ostent 6 como un triunfador, del mismo modo que los anteriores triunfos y los aciertos de algunos de sus presidentes municipales en algunas regiones también canalizaron votos albicelestes (Alonso, 1995: 78).

Pero el autor también explica que el "auge panista" no se puede considerar en sentido estricto, como un voto de castigo ya que esta situación sólo se muestra escasamente en cinco distritos urbanos y uno rural, señala que en todo caso "lo que se dio fue que hubo un auge del voto opositor que benefició al PAN. Este voto panista, que refrendó votaciones anteriores, pero que se allegó de una enorme cantidad de electores nuevos, implicó una opción por la alternancia en la que iba implícita una crítica a la gestión gubernamental, a los problemas no resueltos, a los agravios renovados" (Alonso, 1995: 76) y es que, en términos absolutos, el voto priísta aumentó en ese proceso electoral; no obstante, en la elección para diputados de mayoría éste disminuiría en términos porcentuales alcanzando un $\mathbf{4 3 . 4 \%}$ mientras que el PAN avanzaría con un 40.7 por ciento.

A finales de 1994 y principios de 1995 el clima político le sería más adverso al PRI por varias razones: a nivel nacional, a causa del asesinato de su secretario general, Francisco Ruiz Massieu; por la devaluación del peso cercana al $35 \%$ en febrero de ese mismo año, por el incremento de las tasas de interés, por el alza de precios, de quiebras y cierres de empresas; por las políticas gubernamentales de carácter recesivo, de recorte al gasto público y de incrementos a los impuestos (el IVA) (Valdez, 1996). Aunadas à éstas, las condiciones políticas de Jalisco ya descritas provocarian que el gobierno priista adoptara otra serie de medidas liberalizadoras para calmar los reclamos sociales y políticos, esto se materializaría particularmente con diversas acciones en materia electoral que procurarían "garantizar" una mayor limpieza en los procesos electorales, como son las subsecuentes reformas realizadas por el Congreso del Estado a la Constitución Estatal y a la Ley Electoral, las cuales se encargarian de normar el proceso electoral de 1995 y en las que se dispondría, entre otras cuestiones, la creación del Consejo Electoral; la norma que prohibiría que algún partido político pudiera integrar las dos terceras partes del Congreso, la modificación relativa a la competencia para la calificación de las elecciones y el sistema de impugnación, de modo que los diputados ya no calificarían su propia elección, sino las comisiones distritales; el 
Consejo Electoral sería el que calificaría la elección relacionada con los municipios, aunque, cabe señalar, que la calificación de la elección del gobernador quedaría todavía en manos del Congreso estatal.

De este modo, la difícil situación política de Jalisco - y del paísmotivaría que el gobierno federal advirtiera al prísmo local sobre evitar más conflictos poselectorales y que los dejara a su suerte, no tanto por un afán democrático sino por las posibles implicaciones negativas a nivel nacional (Alonso, 1995). Con lo que en 1995 el PRI pierde la gubernatura, el control del Congreso y numerosos gobiernos municipales; para ser precisos, el paN obtiene 64\% de los escaños en el Congreso, el PRD $2.7 \%$ y el PRI 32.4\%; respecto a los gobiernos municipales, el PAN obtiene 52 gobiernos municipales y el PRD, 6, mientras que el PRI, 63, que si se compara con el año de 1992, difiere en mucho pues el PRI gobernaba 106 municipios y contaba con alrededor de $60 \%$ del voto relativo a la elección de diputados de mayoría, el PAN $31.3 \%$, el PRD obtiene $4.3 \%$, y el PFCRN $2.7 \%$, PARM $1.1 \%$ y el $1 \%$ para el PPS.

Para las elecciones de 1997, el PAN ya habia experimentado los primeros tres años como partido en el gobierno y "padecería" de las llamadas novatadas y críticas por los actos de corrupción y nepotismo existentes en su administración, prevalecería el reclamo relativo a la inseguridad pública en la entidad y la demanda tocante a una reforma política que desmantelara el régimen político autoritario e instaurara otro más acorde con los principios democráticos. Esta última tendría lugar en marzo del año en cuestión y se concretizaría con la reforma en la Constitución local y Ley Electoral, consideradas por diversos investigadores como insuficientes (Marván, Alonso, Preciado, Narro y Osorio, 1998) e incluso como Berrantes (Hurtado, 1998a). Así pues, el 9 de noviembre de ese año se registrarían las elecciones intermedias para diputados locales, en las cuales el PAN obtendría un descenso tanto en términos absolutos como porcentuales en las votaciones. Esta situación le significaría la pérdida del control sobre el Congreso del estado trayendo con ello el primer gobierno dividido. Respecto a esta caída del voto panista, diversos autores señalan al menos dos factores que mediaron en la situación: a) la ausencia de un proyecto de gobierno que coordinara los esfuerzos del partido, el gobierno, y la fracción legislativa del PAN en el Congreso; la ausencia de una agenda legislativa y el tiempo necesario para su negociación; y $b$ ) la ineficacia en el combate a la corrupción. A estos dos se le puede sumar una ineficaz política integral de información y comunicación con la sociedad y/o incapacidad compartida con el partido y el gobierno para incluir e integrar a la sociedad en su proyecto (Marván, Alonso, Preciado, Narro y Osorio, 1998: 116).

En 2000, con el precedente de la victoria de Vicente Fox en la presidencia de República y las votaciones federales ventajosas para el PAN en Jalisco, el panismo local consideraba que este fenomeno se extendería al 
proceso electoral local de noviembre. Sin embargo, eso no sucedería, la recién concluida y prolongada campaña foxista no "Ilegaría" al proceso local pese al aferramiento de los panistas en la entidad; cuestiones como una política social no resuelta $(55 \%$ de la población en Jalisco en la pobreza y $15 \%$ en extrema pobreza); el persistente problema de inseguridad (ocupando el tercer sitio de los estados con mayor inseguridad); las ejecuciones de narcotraficantes; la crisis relativa al lago de Chapala; las irregularidades relativas al gobierno municipal de Zapopan y de otros gobiernos panistas; y la campaña política-electoral de Jorge Arana, serían los posibles factores que motivarian un discernimiento distinto por parte de los electores con respecto a la situación política de Jalisco. Esto sería el preludio del retiro del apoyo a la gestión panista en la gubernatura por parte de no pocos electores en las elecciones locales de 2000.

Ahora bien, con respecto al surgimiento del marketing político, es preciso mencionar que hasta antes de 1994, su uso había sido inexistente por el carácter semicompetitivo del sistema de partidos, porque los procesos electorales no eran otra cosa que actos protocolarios para legitimar al otrora partido hegemónico (Valdez, 2000). En este sentido, es la presencia de procesos electorales más competidos lo que permite, en un primer término, el surgimiento y aplicación de esta técnica en el ambiente políti$c o$, acto seguido serán el tipo de reglamentaciones electorales, el sistema de partidos y los medios de comunicación los que ofrecerán un marco propicio para su desarrollo, y aunque las primeras manifestaciones del marketing político se podrian encontrar en las elecciones de 1994 y 1995 , tal vez se pueda decir que su utilización tiene una mayor presencia en la campaña política del candidato prísta Dau Flores a la presidencia municipal de Guadalajara en 1997, en la que se apoya de uno de los asesores del presidente Clinton; esta estrategia electoral le permitirá poner en la agenda política el tema educativo relativo a la presunta "privatización de la educación por parte del gobierno panista". Éste es el antecedente inmediato a las elecciones locales de Jalisco de 2000 .

\section{El sistema electoral y el desarrollo del marketing politico}

El surgimiento del marketing político en Jalisco sobreviene por la efectiva competencia por el poder entre las diversas fuerzas políticas, empero es el sistema electoral to que ofrece un marco de condiciones favorables para su desarrollo, ya que en éste influirán: 1) el principio de representación mayoritaria, presente al menos en la mitad de los escaños del Congreso del estado; 2) la duración relativamente corta de los periodos

3 Otra estrategia política que valdria la pena subrayar es la llevada a cabo por el gobjemo del PAN y cuyo slogan declaraba "Vamos por un buen camino" y el símbolo del "No retorno". 
de gobierno y de representación política en las presidencias municipales y el Congreso local, mismas que se acortan aún más con la reciente aparición de las primarias y precampañas; 3) el modelo de financiamiento mixto, el cual permite la entrada de recursos privados a los partidos políticos, sin olvidar, por supuesto, la insuficiente normatividad respecto a la fiscalización de los mismos; 4) la escueta reglamentación en lo referente a la comunicación política de los partidos y candidatos durante los procesos electorales, incluso, se puede decir que esto último ha sido un factor casi determinante para el desarrollo de esta técnica. Este razonamiento se obtiene no sólo del análisis de la actual legislación electoral, sino de las diversas legislaciones antecesoras a la establecida en 1997.

\section{La regulación electoral y la comunicación política} partidista (1979 a 1995)

Por lo menos desde la ley electoral de 1979 , se puede decir que en Jalisco se regulaba escasamente la propaganda política utilizada por los partidos durante los procesos electorales, ya que esta cuestión apenas ocupaba ocho artículos en la ley y en ella no se hacía referencia alguna al posible uso de los promocionales en los medios para que los partidos dieran a conocér sus plataformas políticas y sus candidatos. En todo caso, la legislación se limitaba al uso (o prohibición) de la propaganda política en la vía pública (calles, plazas y lugares físicos públicos) y oficinas gubernamentales. Señalaba que la propaganda política debía terminar el día de la elección y dos días anteriores, pero también establecía que quedaban prohibidas "las alusiones ofensivas a las personas, las expresiones verbales o escritas contrarias a la moral, a las buenas costumbres y las que inciten al desorden", del mismo modo que advertía sobre la imposibilidad de utilizar signos o símbolos religiosos, entre otros asuntos. Cabe destacar que en ese mismo año el Ayuntamiento de Guadalajara aprobaría - pero el 22 de septiembre- el "Reglamento sobre fijación de propaganda electoral en la ciudad de Guadalajaran $^{n}$, documento, por cierto, más elaborado (18 artículos), pues además de establecer prohibiciones (y restricciones) respecto a la colocación de propaganda, el marco regulatorio la clasificaría como en provisionales o transitorios, cuasipermantes, y volados o salientes, establecería los requisitos y la tramitación para la obtención de autorizaciones de fijación de propaganda, así como de la aplicación del reglamento, las multas serían de 500.00 a 10000.00 pesos. Cabe agregar que, si bien el Ayuntamiento contaba con una base jurídica importante para remover o impedir la colocación de la propaganda política de los partidos de manera casi arbitraria en algunas ocasiones, es plausible mencionar la finalidad que buscaba; esto es: evitar el uso arbitrario y desordenado de la propaganda, o la mala imagen de la ciudad, así como los posibles accidentes a causa de su mala colocación. 
De cualquier modo, no es sino hasta 1987 cuando el Congreso establece una nueva ley electoral, y aunque no había cambios sustanciales -al menos en lo que respecta al uso de la propaganda política partidista- se establecía que, dentro de las prerrogativas de los partidos, éstos podían recibir propaganda impresa complementaria para el desarrollo de sus campañas políticas, la cual era determinada por el Consejo Electoral del Estado y el número de candidatos que postularan los partidos; asimismo, que gozaban de la exención de impuestos y derechos en "la venta de impresos que editen relacionados con la difusión de sus principios, estatutos, programas y, en general, para su propaganda, asi como por el uso de equipos y medios audiovisuales". A diferencia de la ley anterior, esta medida agregaba lo señalado en cursivas; sin embargo, no queda claro si la norma podía abarcar el uso de los medios de comunicación por parte de los partidos "y gozar de la exención de impuestos". Por otro lado, la ley sería más específica respecto a la conducción de las campañas políticas por parte de los partidos y candidatos, pues prohibiria las expresiones verbales que además injuriaran a las autoridades o a los candidatos de los diversos partidos políticos que contendieran, del mismo modo que ordenaba la suspensión de la celebración de mítines, reuniones públicas o cualquier acto (y fijación) de propaganda política, el día de la elección y los dos días que le precedieran. Por lo demás, se puede decir que la ley mantenía más o menos las mismas prohibiciones respecto a la fijación y contenido de la propaganda política acogida por los partidos.

Después de las presiones políticas motivadas por las ínfimas reformas en el ámbito electoral con fecha del 7 de septiembre de 1991, el Congreso del estado se vio obligado a emprender otra amalgama de modificaciones, las cuales tendrían lugar un poco más de tres meses después, esto es, el 21 de diciembre de ese mismo año. Éste será el preludio de lo que serán las más importantes regulaciones en lo tocante a las campañas políticoelectorales y el uso de los medios de información. A partir de esta reforma es cuando se establece dentro de las prerrogativas de los partidos políticos el tener acceso a las estaciones radiodifusoras y televisoras propiedad de los gobiernos estatal y municipal, asi como la distribución equitativa de los tiempos según la determinación del Consejo Electoral del Estado (art. 27, fr. VIII); de la misma forma, se integra dentro de las prerrogativas "iniciar las campañas electorales de sus candidatos, fórmulas o planillas a partir de las fecha de registro para la elección respectiva y concluirla tres días antes de la elección" (art. 27, fr. VII). Asimismo, se establece la posibilidad de realizar marcbas o reuniones puiblicas (sin más límite que el respeto a los derechos de terceros, en particular de partidos y candidatos, así como las relativas a la preservación del orden público y las buenas costumbres, y lo dispuesto por el articulo $9^{\circ}$ de la Constitución Política de los Estados Unidos Mexicanos) y finalmente, el uso equitativo de las plazas públicas. Se ordena que la propaganda impresa que utilicen 
los candidatos durante la campaña electoral deba contener una identificación precisa del partido político nacional o coalición que haya registrado al candidato. Además, se establece que tanto la propaganda electoral como las actividades de campaña, deban propiciar "la exposición, desarrollo y discusión ante el electorado de los programas y acciones fijados por los partidos políticos nacionales en sus documentos básicos $\mathrm{y}$, particularmente, en la plataforma electoral que para la elección respectiva hubiesen registrado" (art. 29, fr. VI). Por otro lado, se determina que los partidos deberán abstenerse de celebrar mítines, reuniones públicas o cualquier acto de propaganda política el día de la elección y los tres días anteriores a la misma (de esta manera se agrega un día más, esto, con respecto a la anterior ley de 1987), y posteriormente, prohíbe la realización y publicación (en cualquier medio de comunicación) de encuestas durante el día de la elección y los cinco días anteriores a ésta. Hasta aquí, cabe subrayar que la ley todavía había dejado de lado la libre contratación, por parte de los partidos, de promocionales en los medios de información, mientras que a nivel nacional ya se estaba desarrollando una amplia reglamentación en ese terreno.

Sin embargo, serían los acontecimientos acaecidos unos años antes de 1994, e inclusive de ese mismo año, los posibles factores que désencadenarían una mayor liberalización en las reglas electorales. De esta forma, el 4 de agosto de 1994, el Congreso del estado da origen a una nueva ley en la cual se instituye, entre otros aspectos, la obligación de los partidos de "presentar y difundir en la entidad, la plataforma electoral mínima que el partido y candidatos sostendrán en la elección de que se trate, la que deberá registrarse ante el Consejo Electoral del Estado, dentro del plazo de registro de candidatos a que se refiere esta ley" (art. 65, fr. X); del mismo modo que se agrega a la posibilidad de acceder a los medios de propiedad de los gobiernos estatal y municipal, la posibilidad de contratar espacios en las radiodifusoras y televisoras de carácter privado:

[...] tener acceso a las estaciones radiodifusoras y televisoras propiedad de los gobiernos estatal y municipales, respetando en todo caso la programación existente previamente, con tiempo equitativo para todos los partidos políticos, en la forma y términos que determine el Consejo Electoral del Estado. Los partidos politicos con apego a la normatividad respectiva, podrán contratar espacios en estaciones radiodifusoras y televisoras comerciales lart. 67, fr.VII].

Pero también establece lo siguiente:

Tanto la propaganda electoral como los actos de campaña deberán propiciar la exposición, desarrollo y discusión ante el electorado de los programas y acciones propuestas por los partidos polícicos en sus documentos básicos y particularmente, de la plataforma electoral que para la elección respectiva hubiese registrado [art. 69, fr.VI]. 
Por otro lado, se ordena que será el Consejo Electoral del Estado el que determinará los tiempos y espacios oficiales de acceso a los medios de comunicación estatales y municipales, pero además se añade lo siguiente: "y gestionar ante las instancias competentes a petición de los partidos políticos, la posibilidad de contratar a cargo de cada partido político la propaganda de conformidad con la legislación en la materia" [las cursivas son propias]; sin embargo, no se hacía referencia sobre el costo que debían mantener los promocionales políticos de los comerciales (art. 119, fr. XXXVII). Cabe señalar que no es sino hasta 1994 cuando la Ley Electoral establece por primera vez los "topes de campaña" e introduce la incipiente reglamentación en materia de financiamiento privado. Por lo demás, la ley reúne grosso modo las anteriores normas instituidas en legislaciones precedentes las cuales en su mayoria ya fueron abordadas.

Legislación electoral vigente y las campañas electorales en los medios de comunicación

Una vez acaecida la alternancia en el poder, viene el establecimiento de nuevas reglas políticas, y con ella la nueva Ley Electoral, esta última culmina con su aprobación el día 28 de abril de 1997, y establece como obligación de partidos y candidatos el presentar y difundir en la entidad la plataforma electoral mínima en tiempos electorales (art. 63, fr. X), del mismo modo que inscribe dentro de las prerrogativas de los partidos: 1) utilizar espacios de uso común y acceso público para la colocación de propaganda; 2) la fijación de propaganda (previa autorización del particular) en lugares de propiedad privada; 3) el uso de inmuebles públicos (teatros, cines, foros, auditorios) con el objetivo de celebrar actos públicos y privados -debiendo cumplir, en primer término, una serie de requisitos-; 4) la de realizar marchas y reuniones, que en el caso de que impliquen la interrupción de la vialidad, deberán hacer del conocimiento de la autoridad competente, 72 horas antes del día en el que se tenga previsto celebrarse el evento; 5) iniciar las campañas electorales de sus candidatos, fórmulas o planillas a partir del día siguiente en el que se haya declarado válido el registro para la elección respectiva y concluirlas tres días antes del día de la elección; 6 ) tener acceso a las estaciones radiodifusoras y televisoras propiedad de los gobiernos estatal y municipal, del mismo modo que la posibilidad de contratar espacios en estaciones radiodifusoras y televisoras comerciales y; 7) el uso equitativo de las plazas públicas conforme lo dispongan las autoridades competentes.

Dentro de esa misma sección, pero aludiendo al contenido y dirección que deberán guardar las campañas electorales, el artículo 67 es más que explícito al señalar que los partidos no pueden utilizar símbolos, signos ni motivos religiosos, al mismo tiempo que prohibe "las expresiones verbales o alusiones ofensivas a las personas, candidatos y partidos políticos y 
aquéllas contrarias a la moral, a las buenas costumbres y las que inciten al desorden; así como las que injurien a las autoridades o a los candidatos de los diversos partidos políticos que contiendan en la elección". Cabe decir que, con respecto a la propaganda impresa, la ley ordena que ésta deberá contar con una identificación precisa del partido o coalición que haya registrado el candidato, en tanto que la realizada en medios electronicos (radio, prensa, televisión) deberá "especificar claramente que el espacio referido es pagado por el partido, coalición o candidato que realizó la contratación". Ya en su fracción sexta señala que "[...] tanto la propaganda electoral como las actividades de campaña a que se refiere el presente artículo, deberán propiciar la exposición, desarrollo y discusión ante el electorado de los programas y acciones propuestas por los partidos políticos en sus documentos básicos y particularmente, de la plataforma electoral que para la elección respectiva hubiesen registrado". Y finalmente, en la fracción tercera establece que aquella propaganda partidista que se difunda por "medios gráficos" durante una campaña electoral no tendrá más límite "que el respeto a la vida privada de candidatos, autoridades, terceros, a las instituciones y valores democráticos" en los términos del artículo 7 de la Constitución General de la República. Existen otras fracciones como la cuarta y quinta, pero que hacen referencia tanto a los lugares prohibidos para colocar propaganda y el material que deberá ser utilizado en su confección como a lo relativo al cuidado que se deberá tener en el impacto sobre "el entorno natural". Finalmente, el artículo 70 señala que la celebración de mítines, reuniones públicas o "cualquier acto de propaganda política" partidista deberá suspenderse el día de la elección y los tres días anteriores al de la jornada electoral; además, se prohíbe la publicación y difusión de encuestas o preferencias electorales durante la elección (hasta que se cierren las casillas) y los cinco días anteriores al de la jornada electoral (art. 71).

\section{El desempeño de los medios en los procesos electorales en Jalisco}

La exigencia constante de los partidos en México en relación a que los procesos electorales se ajusten a los principios democráticos, ha encontrado cabida también en los medios de información, primero por el acceso, y después por la distribución equitativa de sus espacios; esto debido particularmente a que casi desde sus inicios el partido otrora hegemónico (y por ende, sus candidatos) había recibido un trato privilegiado por parte de los medios en los procesos electorales, incluso hasta los años ochenta (Bohmann, 1986; Trejo, 1991; Arredondo, 1991; Aceves, 2000), cuestión que no resulta extraña si se advierte tanto el sometimiento al cual estaban sujetos los medios, como la complicidad de que habían sido participes no pocos de ellos con el gobiemo. $Y$ es que la tarea encomendada a los medios hasta 
poco antes de 1988 se circunscribía más bien a relatar los sucesos relativos al "destape" del candidato proveniente de las filas del PRI y su consecuente campaña electoral por el territorio de la República (Aceves, 2000a).

$\mathrm{Y}$ aunque el favoritismo de algunos medios por el partido en el gobierno se mantendría en los subsiguientes procesos electorales, este comportamiento se reduciría significativamente en el año 2000 , esto en lo que concierne al aspecto cuantitativo, pues en lo que respecta al contenido informativo (el aspecto cualitativo), es posible observar que el PRI seguiría siendo beneficiado por parte de algunos medios en el año de 1994 (Aceves, 2001) y aún en el proceso electoral del 2000 (Swaan, 2002).

Sin embargo, este cambio en el comportamiento de los medios de información con respecto a la cobertura y tratamiento de la información relativa a las campañas electorales, no sería derivado de una convicción democrática de la mayoría de los medios de información, sino, a lo sumo, por la demanda constante de los partidos de oposición por conseguir una mayor presencia en los medios, por recibir un trato equitativo en la distribución de los espacios, $y$, de ser considerados en la agenda informativa de éstos durante los procesos electorales. De esta manera, las exigencias de los partidos de oposición se traducirían en una serie de reformas que vendrían a afectar las condiciones de la competencia política, garantizando, por lo menos, el acceso a los medios y la distribución igualitaria y equitativa de los espacios y tiempos en éstos; entonces, el cambio impulsado por los partidos de oposición sobrevendría más bien en contra de la voluntad de los medios, que a partir de ellos, aunque no se puede olvidar el esfuerzo de ciertos medios y periodistas por fijar una posición independiente y crítica del gobierno (Aceves, 2000a).

No es sorprendente entonces, por qué el uso del marketing político en México había permanecido ausente en los procesos electorales hasta 1988, pues el sistema de partido hegemónico frenaba la competencia efectiva por el poder; resultaba poco menos que absurdo disentar una complicada campaña electoral si lo determinante no eran los votos, y si además los partidòs de oposición no tenían acceso a los medios o quedaba al arbitrio de sus propietarios, y si la presencia de los partidos de oposición en la agenda de los medios era insignificante.

De ese modo, el uso del marketing político estaría presente en la medida en la que los procesos electorales fueran más competitivos, en la medida en la que los partidos tuvieran acceso a los medios y condiciones más igualitarias y equitativas en la lucha por el poder, en la medida en que los medios se democratizaran e independizaran relativamente del PRI-gobierno; asunto que comenzaría a suceder de manera precipitada desde el año de 1988.

En Jalisco, el tratamiento informativo que los medios habían asignado a los procesos electorales no difiere en mucho del comportamiento de aquéllos de carácter nacional, ya que del mismo modo habrían de estar sometidos y aliados (en algunas ocasiones) con el PRI y el gobierno; 
cuestión que era evidente principalmente en tiempos electorales, pues las campañas electorales de los candidatos provenientes de este instituto político serian privilegiadas en la cobertura informativa de no pocos medios, incluso hasta las elecciones locales de 1995. Así pues, con el estudio de Gilberto Fregoso (1991) relativo a la actividad informativa de los medios situados en Guadalajara sobre el proceso federal electoral de 1988, queda de manifiesto no sólo la exigua importancia que éstos le adjudicaban, por lo menos en ese año, a la cuestión política (ya que este rubro recibiría sólo $2.4 \%$ del espacio total, mientras que la publicidad ocuparía un $49.2 \%$ y los deportes un $8.2 \%$ ) y a los partidos de oposición, pues de ese pequeño material dedicado a la cuestión electoral, los medios le asignarían al PRI $85.05 \%$ del espacio informativo mientras que el PAN y el FDN recibirían $8.32 \%$ y $5.46 \%$ respectivamente.

No obstante, los cambios más significativos sucederían con el proceso federal electoral de 1994, pues en éste, el PRI perdería más la legitimidad entre los jaliscienses, esto a pesar de que los medios en Jalisco mantuvieran su empeño por privilegiar al candidato priísta (aunque en menor proporción); cabe destacar que El Informador y El Occidental le dedicarían incluso tres veces mayor espacio en sus publicaciones que a los dos principales partidos de oposición (el PAN y el PRD). Este patrón se-manifestaría en otros medios impresos y electrónicos pero con diferentes intensidades (Aceves, 2002).4 Ahora bien, si no se había erradicado todavía la preferencia de los medios en su cobertura informativa hacia los candidatos pertenecientes al PRI, por otro lado, la determinación del Consejo General del IFE de realizar un monitoreo de los principales noticieros en radio y televisión sí habría de contribuir a que esa desigualdad se redujera (Aceves, 2000a). Pocos meses después, una medida similar sería adoptada por el Consejo Electoral Estatal para las elecciones locales de 1995; sin embargo, esto no sería suficiente para neutralizar la parcialidad de los medios, ya que los porcentajes que habían destinado los medios al partido en el gobierno meses atrás se incrementarían en esta elección; de este modo, el partido otrora hegemónico se beneficiaría con $66 \%$ del espacio informativo, en tanto que el PAN recibiría $22.8 \%$ y el PRD 5.8\% (Alonso, 1995).5 Situación contraria al proceso local electoral de

1 El periódico El Informador dedicaría $47.9 \%$ al PR, $10.5 \%$ al PAN y $8.4 \%$ al PRD; EI Occidental cubtiría al PRI con $53.8 \%$, al PAN con $10.2 \%$ y al PRD con $12.3 \%$; el peri6dico Siglo 21 le asignaría $32.1 \%$ del espacio al PRI, 11.4\% al PAN, y 13.9\% al PRD. En cuanto a los telenoticiáros, 24 Horas dedicó $28.9 \%$ del tiempo al PRI, $11.5 \%$ al PNN, y $12.6 \%$ al PRD. Telemundo destinó $39 \%$ del tiempo al PRI, $14.7 \%$ al PAN, y 37.2 al PRD.

5 Jorge Alonso señala casos extremos en la cobertura informativa de algunos medios como el periodico Ocbo Columnas que dedica el $77.6 \%$ al PP, $21 \%$ al PAN y nada al PRD; El Informador asigna el $67 \%$ al PR, $15.2 \%$ al PAN y el $5.7 \%$ al PRD; Siglo 21 , en cambio, le otorga $53.8 \%$ al PRI, $27.2 \%$ al PAN, y $13.7 \%$ al PRD; en lo relativo a los noticieros en televisión, Al tanto le dedica el $53.4 \%$ al PRI, el $22.4 \%$ al PAN, y $5.1 \%$ al PRD; Super seis, cubre con $61.3 \%$ al PR, $15.9 \%$ al PAN y con $10.2 \%$ al PRD. (Véase 135, el cambio en jalisco). 
1997, pues en ella la diferencia entre el espacio dedicado en los medios escritos al PRI y la segunda fuerza, el PAN, sería de 6 puntos porcentuales, el espacio asignado al PRI llegaría a un $36.7 \%$, el PAN recibiría $30.3 \%$, y el PRD, 24.4\%. Los medios escritos favorecerían al PRI no sólo en el espacio destinado a este partido, sino en la intencionalidad de las notas, cuestión que se presentaría, asimismo, en los medios electrónicos, pero donde el mayor espacio otorgado no sería al PRI sino al PAN, pues el primero recibiría $27.1 \%$ de la cobertura mientras que el segundo $38.8 \%$, y el PRD el $25 \%$. En el 2000 , los medios observarian profundas diferencias en cuanto a la distribución de los espacios informativos hacia los diversos candidatos de los partidos. La prensa escrita de la zona metropolitana de Guadalajara dedicaria $33.1 \%$ del espacio informativo al PAN, $34.7 \%$ al PRI, y $14.5 \%$ al PRD, mientras que la prensa del interior del estado de Jalisco le asignaría al PAN $23 \%$ de las notas informativas, el PRI recibiría el $49.1 \%$, y el PRD 9.1\%. En el caso de los radionoticieros $37.8 \%$ de las notas serían destinadas al PAN, 29.9\% al PR, y 15.3\% al PRD. En los telenoticieros la distribución de las notas hacia los candidatos de los tres principales partidos del estado de Jalisco sería un "poco más pareja"; así, el PRI recibiría $16.8 \%$ de las notas, el PAN $17.7 \%$, y el PRD $10.8 \%$. Los medios se inclinarian por cubrir las campañas electorales de sólo tres partidos (el PAN, PRI, y PRD) mientras que los otros ocho partidos contendientes quedaban prácticamente en el abandono (Aceves, 2001a). De esta manera, restringieron las ofertas políticas representadas por los diversos partidos, al ceñir en una parte importe su cobertura informativa a las campañas electorales de los tres principales partidos en el estado.

\section{Implicaciones del marketing político en la incipiente democracia jalisciense}

Regulación de las campañas electorales

en los medios de Jalisco

En el caso de Jalisco no se puede decir que la Ley Electoral haya promovido el uso de los medios de información como instrumento de propaganda electoral, al menos no de manera directa, sino que ha sido su carácter laxo lo que ha permitido el desarrollo del marketing político y de la publicidad política mediática, pues aunque ha pretendido seguir los cambios introducidos en el orden federal, dicha ley no ha conseguido grandes avances $o$ innovaciones en la reglamentación de las campañas políticas; por el contrario, las normas actuales no sólo son insuficientes sino que, en ocasiones, no clarifican las condiciones de la competencia por el poder público como son las omisiones de las definiciones de propaganda electoral, de actos de campañas, campaña electoral y de lo 
que abarcan los gastos de campaña. Incluso, parece extraño que los códigos electorales del Estado de México, del Distrito Federal, Baja California, Guanajuato, Sonora, Coahuila y la ley del estado de Hidalgo, consideren los tres primeros términos, y que a los legisladores jaliscienses se les hubiera pasado considerar el significado de estos conceptos y la uniformidad en el texto respecto a la palabra "propaganda electoral", pues hay que señalar que el cuerpo normativo jalisciense hace referencia tanto a "propaganda política" como a la "propaganda electoral". El problema es que la Ley Electoral distingue sólo parcialmente lo que implica una campaña electoral, ya que no incluye este concepto en su cuerpo normativo, caso contrario a otras legislaciones estaduales, pues éstas la enuncian grosso modo como "el conjunto de actividades que los partidos políticos, coaliciones y candidatos llevan a cabo para la promoción del voto en su favor entre el electorado"; incluso la ley electoral de Baja California agrega a los anteriores "las fórmulas o planillas registradas y sus simpatizantes", asunto que se agrava si se analiza, por ejemplo, el artículo 70 , que dicta lo siguiente: "Los partidos políticos deberán suspender la celebración de mítines, reuniones públicas o cualquier otro acto de propaganda política y abstenerse de fijar propaganda el día de la elección y los tres días anteriores al de la jornada electoral", primero, habría que preguntarse si todo mitin o reunión pública implicaría "promover el voto", pues podría ocurrir una manifestación (léase mitin, reunión pública, etcétera) en contra de un acto de alguna autoridad y no necesariamente solicitar el voto de los electores. Ahora bien, el concepto de propaganda política es muy amplio; de nueva cuenta no necesariamente conllevará la búsqueda del voto, aun cuando eso constituya la pretensión última de algún mensaje o acción política.

Tal vez parezca obvio el significado de los anteriores términos; sin embargo, para la seguridad jurídica de los partidos y para la claridad de las reglas de competencia, no resulta innecesaria su definición, ya que esta situación podría significar que el órgano encargado del proceso electoral disfrute de una importante discrecionalidad (y no precisamente autonomía, por lo que puede devenir en una posible parcialidad) en lo que a este tema se refiere; es decir, podría ocurrir en lo posterior una exigua vigilancia con relación a las actividades ejercidas por parte de alguno(s) de los partidos políticos en las campantas electorales, o bien, un exceso en el ejercicio de las facultades de la autoridad hacia los actores políticos, ya que es el propio Consejo Electoral el que establece qué se considera como gasto de campaña y qué no, pero también el que tiene la facultad para reglamentar el acceso y distribución equitativa de los espacios y tiempos en los medios de comunicación de propiedad estatal, así como su posible gestión o no para contratar espacios y tiempos con cargo a los partidos en los medios de carácter comercial y sobre su acceso a los 
mismos, pero principalmente es la autoridad encargada de conducir el proceso electoral. ${ }^{6}$

En cuanto a la afirmación relativa a que la Ley Electoral no ha promovido de manera directa el uso de los medios de información como propaganda política queda sustentada, asimismo, en el hecho de que el estado de Jalisco no subvenciona promocionales para los partidos en los medios de carácter comercial, sino que el apoyo se limita sólo a la publicidad política utilizada en los medios del sector público durante los periodos electorales. Asunto que se suma a la existencia de una ley electoral que ofrece una amplia libertad a los partidos para contratar, prácticamente sin ninguna intermediación, espacios en los medios; incluso, se puede afirmar que en los procesos electorales de 1995 y 1997 también los particulares contaban con la posibilidad para contratar espacios en los medios, dado que todavía no se prohibía que terceros contrataran espacios a favor de algún partido político (esto, al margen de los posibles acuerdos realizados por el Consejo Electoral en esas fechas), pues cabe recordar que no es sino hasta el 6 de agosto de 1998 cuando se establece esa prohibición, con la publicación del "Reglamento de las prerrogativas de acceso de los partidos políticos a los medios de comunicación masivos" texto que, por cierto, otorgaba un papel más activo al Consejo Electoral en lo relacionado a la gestión de los espacios y tiempos en los medios de propiedad estatal y comercial. En este último caso, dicho consejo obligaba a los partidos a comunicar a la autoridad electoral los espacios y tiempos que estuvieran interesados en adquirir, del mismo modo que disponía que el Secretario Ejecutivo debía comunicar a cada uno de los concesionarios o permisionarios, los tiempos y horarios que cada uno de los partidos estuvieran autorizados para comprar con ellos.

Sin embargo, parte de ese reglamento nunca se aplicaría, pues el 29 de julio de 2000 se publicaría la derogación de los artículos $2,6,9,10,11$ y 12 ; esto es, la mitad del cuerpo normativo. De esta manera, el Consejo Electoral se libraba prácticamente de todo vínculo con los medios de comunicación comercial. Los partidos ya no tendrían por qué comunicarle al Consejo los espacios y tiempos que estuvieran interesados en adquirir, así como tampoco el Secretario Ejecutivo tendría por qué comunicar a los concesionarios o permisionarios los tiempos y horarios que cada uno de los partidos estuviera autorizado a contratar, cuestión que viene a significar que hasta el día de hoy, no exista en la Ley Electoral mayor límite al uso de la publicidad política mediática, que la vinculada con los topes de campana y los propios recursos económicos de que dispongan los partidos.

"Cabe decir, que la asignación "equitativa" de los espacios y tiempos en medios de propiedad estatal es de $30 \%$ en partes iguales, y el restante en forma proporcional a ja votación que cada partido hubiera obtenido en la elección local inmediata anterior de diputados de representación proporcional; este formato se mantiene desde 1997. 
Por supuesto que la ausencia de una intermediación entre los medios y los partidos en la contratación de espacios y tiempos viene a debilitar la vigilancia y control sobre los gastos de los partidos y, por ende, a dejarlos al posible amparo de intereses particulares (afectando así la dirección material de la conducta del partido); asunto que adquiere relevancia si se observa que los mayores desembolsos de los partidos se han destinado a este rubro. En ese sentido, el tema de la publicidad política en los medios adquiere importancia no sólo en lo concerniente a la fiscalización, sino dentro de los partidos, en su organización, estrategias, y condiciones para competir por el poder político, pues las campañas electorales se realizan cada vez menos en las antiguas plazas públicas, a las que, por cierto, hacía referencia Habermas, y acontecen con mayor frecuencia en los medios, el nuevo espacio público. En este tenor, la equidad en las condiciones para competir se quebranta en tanto que los espacios y tiempos que reciben los partidos minoritarios son mínimos, y con pocas oportunidades para ingresar a los medios de carácter comercial debido a los elevados costos de colocar un mensaje publicitario, a lo que es preciso agregar los limitados tiempos y espacios que ofrece el Estado en los medios públicos. Del mismo modo, el asunto resulta de gran interés, en el sentido de que la publicidad política mediática se ha convertido en una herramienta comunicativa de los partidos para difundir sus propuestas e influir en la agenda de los medios; en tanto que los medios se han concentrado en la cobertura informativa de sólo algunos partidos e influyen en la conformación de la imagen pública de los partidos y los candidatos.

Así pues, ante unos medios con un papel prácticamente central en el proceso político, el uso de la publicidad política se debe tener en cuenta como un tema obligado en la consideración de las condiciones para competir por el poder político; y es en este asunto que la reglamentación electoral en Jalisco es, hoy por hoy, obsoleta, al ocuparse más de la propaganda que se lleva a cabo en los antiguos espacios públicos, que de la que se desarrolla en los medios, el nuevo espacio público.

En lo relacionado a la reglamentación del contenido de las campañas electorales conviene apuntar que es una cuestión también relegada por los partidos, pues mayor ha sido su preocupación por lograr espacios y tiempos en los medios e incrementar su apoyo electoral que por mejorar el nivel de sus campañas electorales, o por ocuparse, por lo menos, de crear un conjunto de formulaciones o mecanismos que permitan una mejor aplicación del artículo 67 de Ley Electoral estatal, relativa a la propaganda política de los partidos y candidatos, y que no contravenga los artículos 6 y 7 de la Constitución política de México. Mientras tanto, los ciudadanos experimentan un proceso electoral caracterizado por un bajo nivel de propuestas políticas partidistas y en donde las normas actuales parecen no aplicarse por parte de las instituciones que han sido 
creadas para ello o de vigilar que las campañas electorales no se conviertan en una lucha indiscriminada. Este asunto se manifiesta al observar el proceso electoral local de 2000 , y en particular al analizar la publicidad política de los candidatos a gobernador tanto del PRI como del PAN, aunque esto también se puede observar (si se quiere, parcialmente) en la cobertura que hicieron los principales medios de comunicación de Jalisco sobre las campañas electorales de todos los partidos.

\section{Los partidos políticos y la inversión en medios en el proceso electoral de 2000}

En lo que concierne al comportamiento de los partidos durante las campañas electorales, se puede observar su inclinación por utilizar los medios de comunicación como vehículo para dirigirse a los electores. Así lo demuestra la elección de 1997, pues de acuerdo con las estimaciones hechas por una empresa contratada por el Consejo Electoral del Estado de Jalisco (CEEJ), los partidos políticos gastaron cerca de 23 millones de pesos en medios (cuadro 1), de los cuales $56 \%$ fueron destinados a la television, $40 \%$ a la radio y $4 \%$ a la prensa. Sin embargo, a pesar de que las mayores erogaciones fueron dirigidas a promocionales para la televisión, no todos los partidos invirtieron en igual proporción en este medio, pues el PaN, de los más de quince millones de pesos que presuntamente desembols 6 en la campaña política, sólo destinó el $31.9 \%$ de sus recursos a ese medio y $39.9 \%$ a la radio, ${ }^{7}$ comportamiento distinto al de los demás partidos, los cuales destinaron la mayor parte de sus recursos para publicidad política en televisión. Así, llama la atención que los partidos PRD, PT y PVEM hayan dedicado más del $70 \%$ del gasto que realizaron en medios para publicidad política en televisión, ${ }^{B}$ pero que no significó que estos partidos derribaran la supremacía que alcanzó el PAN en los medios, ya que de la inversión total que ejercieron las fuerzas políticas en los medios, el $50 \%$ del dinero invertido correspondió al PAN, en tanto que $18.9 \%$ le perteneció al PRI, $14.07 \%$ al PRD, $11.6 \%$ al PT, y $4.4 \%$ al PVEM. Es importante senalar que en el único medio en donde la competencia política publicitaria fue más "pareja" es en la televisión, pues del desembolso total efectuado por los partidos, 38\% del dinero invertido le perteneció al PAN, cifra que se incrementa de manera significativa a un $50 \%$ en prensa, y a un $68.4 \%$ en la radio.

7 De acuerdo con Jorge Alonso, el PAN reportó en su informe de gastos de campaña $15,516,664.34$ pesos. En lo relativo a los gastos en medios el PAN se estima que destinó en publicidad política 4,957,300.00 en televisión, 6,191,256.00 en radio y $504,629.80$ en prensa. Véase en Democracia Precaria de Jorge Alonso Sánchez, ITESO, 2000, PP. 195-196.

${ }^{8}$ El PRD emplé de su gasto total en medios el $73 \%$ en televisión; el PT 91\%; el PVEM $83 \%$ y el PRI $\mathbf{5 2 \%}$ (Alonso, 2000). 
CUADRo 1. Inversión efectuada por los partidos en medios, en el proceso electoral de 1997

(estimaciones)

\begin{tabular}{lrrrr}
\hline & Televisión & Prensa & \multicolumn{1}{c}{ Radio } & \multicolumn{1}{c}{ Total } \\
\hline PAN & $4,957,300.00$ & $504,629.80$ & $6,191,256.00$ & $11,653,185.80$ \\
PRI & $2,292,666.00$ & $286,074.60$ & $1,774,639.00$ & $4,353,379.60$ \\
PRD & $2,329,569.00$ & $141,759.60$ & $753,280.00$ & $3,224,608.60$ \\
PVEM & $847,068.00$ & & $178,466.00$ & $1,025,534.00$ \\
PT & $2,435,800.00$ & $69,738.00$ & $155,164.00$ & $2,660,702.00$ \\
PC & & & $4,590.00$ & $4,590.00$ \\
PDM & & & & \\
PPS & & $2,576.00$ & & $2,576.00$ \\
TOTAL & $12,862,403.00$ & $1,004,778.00$ & $9,057,395.00$ & $22,924,576.00$ \\
\hline
\end{tabular}

Fuente: (Alonso, 2000)

Inclusive algunos partidos habrían sobrepasado los topes de campaña sólo por los gastos invertidos en los medios, conforme a las estimaciones antes aludidas. Como es el caso de la elección en el municipto de Zapopan, en la que tanto el PRI como el PAN posiblemente gastaron más de un millón cuatrocientos cada uno en promocionales en prensa, radio y televisión (el PRI gastó 1,406,049.00 y el PAN 1,486,647.00 de pesos). Esto es sin considerar que el tope establecido para este municipio era de un $1,359,249.96$ pesos; es decir, ambos partidos habrian rebasado el tope de campaña sólo en gastos en medios; otras erogaciones que merecen ser mencionadas son las llevadas a cabo por el PAN en Guadalajara, que virtualmente invirtió más de dos millones de pesos (para ser exactos $2,515,563.50$ de pesos) en promocionales para la elección del presidente municipal de Guadalajara. Cabe agregar que el tope de campaña para este municipio era de casi tres millones de pesos. Lo que significa, en otras palabras, que el PAN habría alcanzado $80 \%$ del gasto permitido para publicidad en medios. 9

En el proceso electoral de 2000 , si bien parece que ningún partido sobrepaso los topes de campaña establecidos para la elección de gobernador y presidentes municipales de Guadalajara, Zapopan, Tonalá y Tlaquepaque (cuadro 2), la inclinación de los partidos por invertir en los medios se mantuvo, del mismo modo que se volvieron a presentar las

\footnotetext{
${ }^{9}$ Aunque de acuerdo con los informes financieros de los partidos ninguno sobrepasó los topes de campaña, la fiscalización de los recursos a cargo del Consejo Electoral del Estado de Jalisco llevó a que se impusieran diversas amonestaciones, reducciones en algunas de las administraciones relativas al financiamiento público y multas a los partidos, esto a causa de las irregularidades encontradas en los informes financieros de los partidos. Cabe decir que una parte de la información vinculada a gastos en medios fue ocultada al cEeJ.
} 
irregularidades de los principales partidos (PAN, PRI, PRD) en cuanto a sus informes financieros relativos a los gastos efectivamente realizados en los medios (Alonso, 2002: 214).

Cabe señalar que el proceso electoral de 2000 revela, de nueva cuenta, la superioridad que alcanza el PAN en lo que concierne a presencia en medios a través del uso de la publicidad política, al menos en la elección de los presidentes municipales de Guadalajara, Zapopan y Tonalá, y en la elección de gobernador (cuadro 3). Así, mientras en Guadalajara el PRI gasta $16.7 \%$ y el PRD $7.9 \%$ del egreso total destinado por todos los partidos a los medios, el PAN lo hace con $72.7 \%$; cifra que aumenta a un $76.2 \%$ en el municipio de Zapopan en tanto que el PRI y el PRD cubren 9.4\% y $14.1 \%$ respectivamente. Sin embargo, el porcentaje de participación que alcanza el PAN con relación a los gastos realizados por todas las fuerzas políticas en los medios, se eleva aún más en el municipio de Tonalá, pues ahí el PAN ocupa $82.5 \%$ del gasto total ejercido por todos mientras que el PRI destina $15.7 \%$ y el PRD $1 \%$; finalmente, en la elección de gobernador, la distancia entre los gastos realizados por los dos principales partidos representados en el Congreso disminuye, ya que el PAN consigue $48.6 \%$ del desembolso total destinado por todos los partidos a los medios, en tanto que el PRI logra $39.4 \%$, y el PRD $9.4 \%$. Un asunto que llama la atención es que en el municipio de Tlaquepaque no es el pan el partido que más participación tiene con respecto a los gastos efectuados por todos los partidos en medios, sino el PRD con un $44.7 \%$ mientras que el PRI y el PAN alcanzan un $9.9 \%$ y un $20.7 \%$ respectivamente, incluso el PARM participó con $19: 9$ por ciento.

CUADRO 3, Inversión en publicidad política mediática, en el proceso electoral local de 2000

\begin{tabular}{lrrrrr}
\hline & Guadalajara & Zapopan & Tlaquepaque & Tonala & Gobernador \\
\hline PAN & $3,460,863.17$ & $1,717,888.71$ & $145,620.08$ & $428,882.87$ & $11,662,834.50$ \\
PRI & $796,300.00$ & $213,217.00$ & $70,000.00$ & $81,559.00$ & $9,460,197.24$ \\
PRD & $378,741.92$ & $318,173.43$ & $314,485.49$ & $5,277.35$ & $2,262,172.74$ \\
PT & & & & & $216,540.00$ \\
PVEM & & & $29,498.48$ & & \\
CD & 920.00 & & & & \\
PCD & & & & & \\
PSN & $113,575.00$ & & $139,972.19$ & & \\
PARM & $10,232.83$ & $3,908.18$ & $3,907.83$ & $3,907.83$ & $8,988.00$ \\
PAS & & & & & \\
PDS & & & & & \\
\hline
\end{tabular}

Fuente: CEES. 
Entonces, el PAN es el partido que más invierte en medios y el que mayor presencia tiene en éstos, cosa que queda en evidencia si se remite a los spots partidistas transmitidos por los medios, en los que destaca la difusión en televisión de 1,602 spots del PAN, 1,424 del PR, 441 del PRD, 251 del PT, y 50 de CD. En lo que concierne a la publicidad política en radio, el PAN de nueva cuenta supera a los otros partidos con la transmisión de 13,809 spots, en tanto que los anuncios de su más cercano competidor, el PRI, alcanzan la cifra de 8,968; cabe decir que 4,100 spots pertenecieron al PRD, 1,557 al CD, 970 al PDS, y 564 al PT, mientras que en prensa, el PAN se anunciaría en 5.30 paginas, el PRI en 4.57; el PVEM en 1, el PDS en 0.30; el PAS en 1.76 y CD en 22 páginas.

Para obtener una perspectiva de la competencia política desarrollada en los medios, a través del uso de la publicidad política, y en particular de aquélla vinculada con los partidos PRI, PAN y PRD en el proceso local de 2000 , es posible remitirse a las cifras proporcionadas por la empresa Contacto, las cuales revelan que los ciudadanos (por no decir la población) estuvieron expuestos, del 28 de agosto al 5 de noviembre, a más de 27,000 mensajes promocionales en los medios de información (exactamente, 27,688), de los cuales 2,814 se transmitieron por televisión y 24,874 por radio; lo cual implica la transmisión de casi 400 promocionales diarios. Por orro lado, si se toman en cuenta los promocionales en medios de los partidos PRI, PAN y PRD de las elecciones federales de ese mismo año, la empresa Contacto señala que, del 1 de mayo al 25 de junio, se transmitieron 55 comerciales diarios en televisión y 633 spots en radio, lo que significa, en otras palabras, que el elector estuvo expuesto en total a más de 3,000 mensajes publicitarios en televisión y a casi 35,000 promocionales en la radio (Marlín, 2001: 78-79).

Pero entonces, ¿de los egresos totales efectuados por cada uno de los partidos en las campañas electorales de ese año, ¿qué porcentaje destinaron para promocionar las candidaturas de sus respectivos candidatos en los medios? De acuerdo con Alonso (2002), el que mayor porcentaje de dinero destino a medios fue el PAN con $52.7 \%$, en seguida el PRD con $48.7 \%$, y el PRI con $48.7 \%$, en tanto que otros partidos destinaron menos de $40 \%$, como son los casos del Parm $(34.4 \%)$, el CD $(24.1 \%)$, el PAs (18.1\%) y el PT con $12.3 \%$, los restantes partidos destinaron menos de 5 por ciento.

Sin embargo, en las elecciones para presidentes municipales de Guadalajara, Zapopan, Tonalá y Tlaquepaque, los principales partidos destinarían, en ocasiones, más de $50 \%$ de sus egresos generales, para publicidad política en medios (cuadro 4). Así, en Guadalajara, el PAN emplearía $66.1 \%$ de sus recursos para gastos en medios mientras que el PRI usaría 55.2\%. En Tlaquepaque, el PRD utilizaría $68.8 \%$ mientras que el PRI y el PAN gastarían $30.2 \%$ y $28.2 \%$ respectivamente. En Tonală, el PAN destinaría $74.1 \%$ en tanto que en Zapopan gastaría $72.3 \%$ y el PRD $58.9 \%$. 
Del modo que sea, es en la campaña electoral para gobernador en la que el PAN, PRI y PRD destinan mayor porcentaje para gastos en medios, pues el PAN dedica $64.3 \%$, el PRI $70.6 \%$ mientras que el PRD gasta el 75 por ciento.

CUADRo 4. Inversión efectuada por el PAN, PRI, PRD en medios (1997-2003)

\begin{tabular}{|c|c|c|c|c|}
\hline \multicolumn{5}{|c|}{ proceso electoral local de 1997} \\
\hline & Guadalajara & Zapopan & Thaquepaque & Tonala \\
\hline $\begin{array}{l}\text { PAN } \\
\text { PRI } \\
\text { PRD }\end{array}$ & $\begin{array}{c}1,125,413.23 \\
901,823.31\end{array}$ & $\begin{array}{l}711,974.50 \\
636,645.65\end{array}$ & & $12,858.39$ \\
\hline \multicolumn{5}{|c|}{ Proceso electoral local de 2000} \\
\hline & Guadalajara & Zapopan & Thaquepaque & Tonald \\
\hline $\begin{array}{l}\text { PAN } \\
\text { PRI } \\
\text { PRD }\end{array}$ & $\begin{array}{c}3,460,863.17 \\
796,300.00 \\
378,741.92\end{array}$ & $\begin{array}{r}1,717,888.71 \\
213,217.00 \\
318,173.43\end{array}$ & $\begin{array}{r}145,620.08 \\
70,000.00 \\
314,485.49\end{array}$ & $\begin{array}{r}428,882.87 \\
81,559.00 \\
5,277.35\end{array}$ \\
\hline & \multicolumn{3}{|c|}{ Proceso electoral de 2003} & + \\
\hline & Guadalajara & Zapopan & Tlaquepaque & Tomala \\
\hline $\begin{array}{l}\text { PAN } \\
\text { PRI } \\
\text { PRD }\end{array}$ & $\begin{array}{c}5.361 .359 .74 \\
4.282 .980 .74 \\
170.650 .72\end{array}$ & $\begin{array}{c}3.601 .486 .50 \\
1.050 .113 .73 \\
91.313 .52\end{array}$ & $\begin{array}{c}1.076 .339 .17 \\
86.894 .00 \\
3.915 .15\end{array}$ & $\begin{array}{r}505.439 .61 \\
2.610 .10\end{array}$ \\
\hline
\end{tabular}

Fuente: CEEJ.

\section{Consideraciones finales}

Dos han sido los objetivos buscados por el presente estudio: 1) Describir y examinar los elementos del sistema político y el sistema de medios causantes del surgimiento y desarrollo del marketing político en el entorno jalisciense, y; 2) Explicar y reunir diversas variables de análisis para la comprensión teórica del marketing político.

En cuanto al primer punto, el estudio señala que la emergencia del marketing político en Jalisco no es fortuita, la presencia de diversos elementos en el sistema político y los medios de información, parecen demostrarlo, incluso, se puede afirmar que, algunas de las veces, el uso del marketing político ha sido propiciado por los mismos partidos, lo cual se puede observar a través de las distintas modificaciones a la Ley Electoral (el sistema electoral), y específicamente, por el carácter laxo de la Ley Electoral y el interés de los partidos en el acceso y distribución equitativa de los espacios y tiempos en los medios durante los procesos electorales; a esta conducta se le agrega la tendencia a invertir cada vez más en 
publicidad política mediática, asunto que merece ser destacado, ya que la libertad que tienen los partidos para contratar espacios y tiempos en los medios constituye uno de los mayores incentivos para el uso del marketing político.

La gradual democratización de los medios impulsada más bien por las diversas fuerzas de oposición es otro factor que ha condicionado, en buena parte, el desarrollo del marketing político, por lo que no es de extrañar el insignificante o nulo uso de esta técnica hasta poco antes de los procesos electorales de 1994, máxime si el sistema de partido hegemónico frenaba la competencia efectiva por el poder, si resultaba poco menos que insensato diseñar una complicada campaña electoral, si lo determinante no eran los votos, si además los partidos de oposición no tenían acceso a los medios o quedaba al arbitrio de sus propietarios colocar los mensajes publicitarios, si la presencia de los partidos de oposición en la agenda de los medios era insignificante; a lo anterior, cabe agregar la intervención cada vez más importante de los medios -a través de sus diversas formas- en los procesos políticos, y en particular, durante los procesos electorales (Aceves, 2000; 2000a; 2001; 2002), pero también su conformación como nuevo espacio público y lugar privilegiado de la política, asunto que queda en evidencia, si bien parcialmente, por medio de los gastos ejercidos por los partidos en los recientes procesos electorales y, por supuesto, por la capacidad que tienen los medios (principalmente la television) de llegar a un importante auditorio.

No obstante, es el sistema electoral el que se convertiráa aquí en un incentivo importante para el uso del marketing político, en particular por la débil regulación de las campañas, pues cabe recordar que las más importantes reformas en el ámbito electoral ocurren hasta 1991, 1994 y 1997. A partir de esas fechas, un conjunto de libertades son provistas para los partidos, se establece primero, en 1991, la posibilidad para disponer de espacios en los medios de propiedad estatal, y después, en 1994, se otorga la capacidad para contratar tiempos y espacios en los medios privados, se determina, también, por vez primera, los "topes de campaña" aunque no habrá sanciones para aquellos, que los rebasen, del mismo modo que se introduce la incipiente reglamentación en materia de financiamiento privado y la disposición que indica que el Consejo Electoral intervenga, a petición de los partidos, en la contratación de espacios en los medios con cargo a aquéllos, todo lo anterior hasta 1994. Por supuesto que estos cambios a la Ley Electoral, vendrán acompañados por procesos electorales más competidos, por la demanda constante de los partidos de oposición en relación a que las elecciones se ajusten a los principios democráticos, pero también por la alternancia en el poder y la reforma política, con lo que después se creará la Ley Electoral de 1997.

Sin embargo, esa misma ley es por mucho insuficiente, pues hasta hoy no clarifica las condiciones de la competencia por el poder político; así, 
Del modo que sea, es en la campaña electoral para gobernador en la que el PAN, PRI y PRD destinan mayor porcentaje para gastos en medios, pues el PAN dedica $64.3 \%$, el PRI $70.6 \%$ mientras que el PRD gasta el 75 por ciento.

CUADRo 4. Inversión efectuada por el PAN, PRI, PRD en medios (1997-2003)

\begin{tabular}{|c|c|c|c|c|}
\hline \multicolumn{5}{|c|}{ proceso electoral local de 1997} \\
\hline & Guadalajara & Zapopan & Thaquepaque & Tonala \\
\hline $\begin{array}{l}\text { PAN } \\
\text { PRI } \\
\text { PRD }\end{array}$ & $\begin{array}{c}1,125,413.23 \\
901,823.31\end{array}$ & $\begin{array}{l}711,974.50 \\
636,645.65\end{array}$ & & $12,858.39$ \\
\hline \multicolumn{5}{|c|}{ Proceso electoral local de 2000} \\
\hline & Guadalajara & Zapopan & Thaquepaque & Tonald \\
\hline $\begin{array}{l}\text { PAN } \\
\text { PRI } \\
\text { PRD }\end{array}$ & $\begin{array}{c}3,460,863.17 \\
796,300.00 \\
378,741.92\end{array}$ & $\begin{array}{r}1,717,888.71 \\
213,217.00 \\
318,173.43\end{array}$ & $\begin{array}{r}145,620.08 \\
70,000.00 \\
314,485.49\end{array}$ & $\begin{array}{r}428,882.87 \\
81,559.00 \\
5,277.35\end{array}$ \\
\hline & \multicolumn{3}{|c|}{ Proceso electoral de 2003} & + \\
\hline & Guadalajara & Zapopan & Tlaquepaque & Tomala \\
\hline $\begin{array}{l}\text { PAN } \\
\text { PRI } \\
\text { PRD }\end{array}$ & $\begin{array}{c}5.361 .359 .74 \\
4.282 .980 .74 \\
170.650 .72\end{array}$ & $\begin{array}{c}3.601 .486 .50 \\
1.050 .113 .73 \\
91.313 .52\end{array}$ & $\begin{array}{c}1.076 .339 .17 \\
86.894 .00 \\
3.915 .15\end{array}$ & $\begin{array}{r}505.439 .61 \\
2.610 .10\end{array}$ \\
\hline
\end{tabular}

Fuente: CEEJ.

\section{Consideraciones finales}

Dos han sido los objetivos buscados por el presente estudio: 1) Describir y examinar los elementos del sistema político y el sistema de medios causantes del surgimiento y desarrollo del marketing político en el entorno jalisciense, y; 2) Explicar y reunir diversas variables de análisis para la comprensión teórica del marketing político.

En cuanto al primer punto, el estudio señala que la emergencia del marketing político en Jalisco no es fortuita, la presencia de diversos elementos en el sistema político y los medios de información, parecen demostrarlo, incluso, se puede afirmar que, algunas de las veces, el uso del marketing político ha sido propiciado por los mismos partidos, lo cual se puede observar a través de las distintas modificaciones a la Ley Electoral (el sistema electoral), y específicamente, por el carácter laxo de la Ley Electoral y el interés de los partidos en el acceso y distribución equitativa de los espacios y tiempos en los medios durante los procesos electorales; a esta conducta se le agrega la tendencia a invertir cada vez más en 
publicidad política mediática, asunto que merece ser destacado, ya que la libertad que tienen los partidos para contratar espacios y tiempos en los medios constituye uno de los mayores incentivos para el uso del marketing político.

La gradual democratización de los medios impulsada más bien por las diversas fuerzas de oposición es otro factor que ha condicionado, en buena parte, el desarrollo del marketing político, por lo que no es de extrañar el insignificante o nulo uso de esta técnica hasta poco antes de los procesos electorales de 1994, máxime si el sistema de partido hegemónico frenaba la competencia efectiva por el poder, si resultaba poco menos que insensato diseñar una complicada campaña electoral, si lo determinante no eran los votos, si además los partidos de oposición no tenían acceso a los medios o quedaba al arbitrio de sus propietarios colocar los mensajes publicitarios, si la presencia de los partidos de oposición en la agenda de los medios era insignificante; a lo anterior, cabe agregar la intervención cada vez más importante de los medios -a través de sus diversas formas- en los procesos políticos, y en particular, durante los procesos electorales (Aceves, 2000; 2000a; 2001; 2002), pero también su conformación como nuevo espacio público y lugar privilegiado de la política, asunto que queda en evidencia, si bien parcialmente, por medio de los gastos ejercidos por los partidos en los recientes procesos electorales y, por supuesto, por la capacidad que tienen los medios (principalmente la television) de llegar a un importante auditorio.

No obstante, es el sistema electoral el que se convertiráa aquí en un incentivo importante para el uso del marketing político, en particular por la débil regulación de las campañas, pues cabe recordar que las más importantes reformas en el ámbito electoral ocurren hasta 1991, 1994 y 1997. A partir de esas fechas, un conjunto de libertades son provistas para los partidos, se establece primero, en 1991, la posibilidad para disponer de espacios en los medios de propiedad estatal, y después, en 1994, se otorga la capacidad para contratar tiempos y espacios en los medios privados, se determina, también, por vez primera, los "topes de campaña" aunque no habrá sanciones para aquellos, que los rebasen, del mismo modo que se introduce la incipiente reglamentación en materia de financiamiento privado y la disposición que indica que el Consejo Electoral intervenga, a petición de los partidos, en la contratación de espacios en los medios con cargo a aquéllos, todo lo anterior hasta 1994. Por supuesto que estos cambios a la Ley Electoral, vendrán acompañados por procesos electorales más competidos, por la demanda constante de los partidos de oposición en relación a que las elecciones se ajusten a los principios democráticos, pero también por la alternancia en el poder y la reforma política, con lo que después se creará la Ley Electoral de 1997.

Sin embargo, esa misma ley es por mucho insuficiente, pues hasta hoy no clarifica las condiciones de la competencia por el poder político; así, 
se pueden encontrar omisiones de diversas definiciones en la Ley Electoral con relación a conceptos tales como propaganda electoral, actos de campañas, campaña electoral y lo que comprenden los gastos de campaña; se puede observar, además, cierta discrecionalidad (y no precisamente autonomía) de la que goza el Consejo Electoral en ciertos aspectos y que puede devenir en parcialidad, pero también la laxa regulación en lo relativo a las campañas electorales en los medios, pues cabe señalar que hasta 1997 todavía no se prohibía a los particulares la posibilidad para contratar promocionales en los medios a favor de un partido político. Incluso, del conjunto de regulaciones que surgen en 1998 en materia de acceso a medios masivos, la mitad del cuerpo normativo es eliminado por el propio Consejo Electoral a unos días de iniciar el proceso electoral de 2000 , de manera que éste quedaba prácticamente librado de todo vínculo con los medios.

En este sentido, la insuficiente regulación de las campañas electorales adquiere importancia en la medida en que éstas ocurren en los medios y para los medios —el nuevo espacio público- y cada vez menos en las antiguas plazas públicas, aquéllas a las que hacía referencia Habermas; si además, se toma en consideración que la publicidad política mediática (aquélla que está apoyada en estudios de marketing) se ha convertido en la principal herramienta comunicativa de los partidos para difundir sus propuestas e influir tanto en la opinión pública como en la agenda noticiosa de los medios, si se observa, también, el papel prácticamente central que han obtenido los medios de información en los procesos políticos al influir (entre otras cuestiones) de manera decisiva en la conformación de la imagen pública de los partidos y candidatos, pero tambiên, por la parcial cobertura informativa que ban producido los medios en Jalisco, al restringir la agenda de lo socialmente relevante a tan sólo algunos de los actores politicos, cuestión que viene a quebrantar la equidad que debe guardar el proceso electoral (Aceves, 2001a), a lo que se le suma, el exiguo espacio y tiempo en medios que reciben los partidos minoritarios por parte del estado, en tanto que la posibilidad para contratar espacios en los medios se reduce considerablemente por los elevados costos.

Así pues, ante unos medios con un papel prácticamente central en el proceso democrático, el uso de la publicidad política se debe considerar como un tema obligado en la consideración de las condiciones para competir por el poder político, por sus implicaciones dentro de los partidos, en su organización, estrategias, y fiscalización, y es, por todo lo anterior, que la reglamentación electoral en Jalisco es, hoy por hoy, obsoleta.

Sin embargo $-y$ aquí radica la importancia de posteriores estudios sobre este tema-, si se parte de que la publicidad política no busca informar sino persuadir o seducir al elector, que en los mensajes publicitarios se privilegia al candidato sobre las propuestas (en virtud de que 
aún éstas sirven para formar o fortalecer la imagen del candidato); ${ }^{10}$ que las campañas electorales ocurren cada vez más en los medios y se invierte progresivamente en anuncios, entonces ello nos advierte, en cierta medi$\mathrm{da}$, de que lo que los candidatos manifiestan en sus mensajes publicitarios puede ser cualquier cosa, menos propuestas políticas, y que sus discursos pueden estar muy lejos de las necesidades reales de la población mexicana. De ser cierto todo lo anterior, entonces la democracia mexicana (y la jalisciense) está en riesgo.

\section{Bibliografia}

Aceves González, Francisco (2000), "Los medios de comunicación y el electorado tapatio en las elecciones presidenciales de 1994. La construcción de la imagen pública de los candidatos presidenciales y su impacto en la percepción de los usuarios", tesis de Doctorado en Ciencias Sociales, Universidad de Guadalajara/cIESAS de Occidente.

- (2000a), "Ia investigación académica sobre el papel de los medios de comunicación en los procesos electorales en México", en Comunicactón y Sociedad, núm. 37, Universidad de Guadalajara, enero-junio.

- (2001), "El papel de los medios en la construcción de los temas (issues) electorales. El caso de las elecciones presidenciales de 1994 en México", en J. L. Cerdán y F. Aceves G. (eds.), Anuario de investigación de la comunicación, coneicc, México.

- (2001a), "Los medios de comunicación y las elecciones estatales de 2000", en Jalisco: elecctones 2000. Análisis, Consejo Electoral del Estado de Jalisco (CEEJ), México.

- (2002), Los medios y la construcción de la imagen püiblica. Las elecciones de 1994 en México, Colección de Babel, núm. 23, Universidad de Guadalajara, México.

Alonso, Jorge (1986), "Sociedad y gobierno en la coyuntura de las explosiones", en R. Reguillo y C. Padilla (eds.), Quién nos bubiera dicbo, Guadalajara, ITESO, 22 de abril.

- (1993), El rito electoral en Jalisco (1940-1992), Colegio de Jalisco, México. (1995), El cambio en Jalisco. Las elecciones de 1994 y 1995, CUCSH/CEE/ CIESAS-Occidente, México,

- (2000), Democracia precaria, ITEso, México.

- (2002), Democracia amenazada, ITESo, México.

Arredondo, Pablo (1991), "Los medios de comunicación en la lucha político-electoral", en P. Arredondo, G. Fregoso y R. Trejo D. (eds.), Así se callo el sistema. Comunicactón y elecciones en 1988, Universidad de Guadalajara, México.

${ }^{10}$ De acuerdo con Kaid (1999) y Johnston (2001) el mejoramiento de la imagen del candidato se puede lograr, incluso, a través de los spots orientados a temas. Esto es necesario destacarlo ya que no es únicamente mediante la publicidad política orientada a la "imagen" del candidato que se puede lograr mejoras la percepción (imagen pública) de los candidatos frente al electorado. 
Bohmann, Karin (1986), Medios de comunicación y sistemas informativas en México, 2a ed., Alianza, México.

Delarbre, Raúl (2001), Mediocracia sin mediaciones: prensa, televisión y elecciones, Cal y Arena, México.

Ferrer, Eulalio (1995), De la lucba de clases a la lucba de frases, Taurus, México. Fregoso, Gilberto (1991), "Análisis sobre información política en la prensa de Guadalajara: la sucesión presidencial", en P. Arredondo, G. Fregoso y R. Trejo (eds.), Asi se calló el sistema. Comunicación y elecciones en 1988, Universidad de Guadalajara, México.

Habermas, J. (1997), Historia y crítica de la opinión püblica , 5’ ed., G. Gilli., España

Hennerberg Sthephan (2002), N. J. O'Shaughnessy y S. C.M. Hennerberg (eds.), Understanding political marketing, The Idea of Political Marketing, Praeger., Londres

Hurtado, Javier (1998), Sistema político en Jalisco, Universidad de Guadalajara/ CEPCOM, México.

- (1998a), "Reformas sin ismos", en J. Hurtado y A. Valdez Zepeda (eds.), Demacracia y poder político en Jalisco. Desde la alternancia basta las elecctones de 1997, Universidad de Guadalajara, México.

Johnston, Anne (2001), "Videostyle differences in issue and image ads. Comparing televised Presidential Ads form 1952-2000", presentado en American Political Science Associate Convention, agosto-septiembre.

Kaid, Lynda Lee (1999), "Political advertising: A summary of research findings", en Bruce I. Newman (ed.), Handbook of political marketing, Sage, Estados Unidos.

Lujambio, Alonso (1995), Federalismo y Congreso en el cambio político de México, uNaM, México.

(2000), El poder compartido. Un ensayo sobre la democratización mexicana, Océano, México.

Maarek, Philippe (1997), Marketing politico y comunicación. Claves para una buena información política, Paidos, España.

Marlín, Rubén, "¿̨or qué no votan los ciudadanos" Abstencionismo, caliłtad de la política y sociedad, en las últimas elecciones en Jalisco", en Jalisco, elecciones 2000, análisis, Consejo Electoral del Estado de Jalisco (CEEJ), México.

Marván, M., J. Alonso, J. Preciado C., J. Narro M., y G. J. Osorio (1998) "Conflicto y consenso: la alternancia y el dificil proceso de construcción de un régimen distinto", en L. R. Gallardo Gómez, S. R. de Dios Corona, M. Marván L., J. Osorio G., J. Regalado S., E. Valencia (eds.), Jalisco tres años de alternancia, ITESO/Universidad de Guadalajara, México.

Morato, Javier del Rey (1989), La comuntcación política. (El mito de las izquierdas $y$ derecbas), Eudema, España.

Plasser, Fritz, Christian Scheuchery y Christian Senft (1999), "Is there a European Style of Political Marketing: A Survey of Political Managers and Consultants", Bruce I. Neuman (ed.), Handbook of political marketing, Sage, Estados Unidos.

Priess, Frank (2000), "La hegemonía del marketing político en América Latina", en Etcétera, mayo, México.

Salgado, Lourdes Martín (2002), Marketing politico. Arte y ciencia de la perstuasión en democracia, Paidos, Barcelona. 
Sánchez Murillo, Luis Fernando (2003), "El uso del marketing político y su incidencia en la democracia jalisciense", tesis de Licenciatura, Universidad de Guadalajara.

Swaan, Mony (2002), 'En 2000, las televisoras votaron por el PRI", en Etcétera, núm. 26, diciembre.

Trejo, Raúl (1991), "Campañas y elecciones en la prensa en la ciudad de México", en P. Arredondo, G. Fregoso y R. Trejo D. (eds.), Así se calló el sistema. Comunicación y elecciones en 1988, Universidad de Guadalajara, México.

Valdez, Andrés (1996), El partido Acción Nactonal y la transición política en Mëxico.

(2000). Mercadotecnia política. El estado actual de la disciplina en México, Arrayán, México. 